\title{
Assessment of the Toxic Potential of Carbosulfan in Rats Following Subchronic Treatment
}

\author{
Ines El-Bini Dhouib ${ }^{1 *}$, Maha Abdeladhim ${ }^{2}$, Mohamed Montassar Lasram ${ }^{1}$, Alya \\ Annabi $^{1}$, NajouaGharbi ${ }^{1}$, Melika Ben Ahmed ${ }^{2,3}$, Saloua El-Fazaa ${ }^{1}$ \\ ${ }^{1}$ Laboratory of physiology of the aggressions, department of biology, Faculty of Sciences of Tunis, Campus \\ Universitaire, 2092 Manar II, Tunis, Tunisia \\ ${ }^{2}$ Laboratory of Clinical Immunology, Pasteur Institute of Tunis, Tunis, Tunisia \\ ${ }^{3}$ Faculty of Medicine of Tunis, University of Tunis ElManar, Tunisia
}

\begin{abstract}
The effect of Carbosulfan (CB), a carbamate insecticide which has been used widely in agriculture, was investigated using wistar rat. Carbosulfan was administered orally at sublethal concentration at a dose of $25 \mathrm{mg} / \mathrm{kg}$ to 12 male rats ad libitum during the tests for 30 days consecutively. The effect of $C B$ on hematological constituent [Red Blood Corpuscules (RBC), White Blood Corpuscules (WBC), Mean Cell Volume $(\mathrm{MCV})$, Mean Corpuscular Hemoglobin (MCH), Mean Corpuscular Hemoglobin Concentration (MCHC), platelet (PLT) Hemoglobin (HGB) and Hematocrit (HCT) levels] and serum damage marker enzymes [aspartate aminotransferase (AST), alanin aminotransferase (ALT), alkaline phosphatase (ALP) and lactate dehydrogenase $(L D H)]$ of rats were investigated under laboratory conditions .Body weight, organ weight, cellularity of spleen, spleen cell subtypes, cytokine production and lymphocyte proliferation assay were also studied. CB treatments caused different effects on the hematological constituents and the serum marker enzymes of the treatment groups as compared to the controls. Results showed that $C B$-treated group had a significantly lower RBC, HGB, HCT, MCV, MCH and MCHC and significantly higher WBC and PLT. Also, serum marker enzymes were affected by $C B$. For example, ALT, $A L P$, creatinine and urea significantly increased in rats treated with $C B$. Our data showed that $C B$ at $25 \mathrm{mg} / \mathrm{kg} /$ day could suppress cellular activity of the immune system. At this dose, CB significantly decreased the proliferation response to PHA and the production of IFN gamma and IL-4.
\end{abstract}

Keywords: Carbosulfan; immunotoxicity; spleen; hematotoxicity; hepatotoxicity; nephrotoxicity.

\section{Introduction}

Several hundred of pesticides have been synthesized and used in agricultural practices in order to ameliorate vegetables, fruits and other culture products by eradicating annoying insects. Public health programs in many developing countries use pesticides as insecticides of choice to control disease-transmitting organisms. It is more evident that many pesticides produce their acute toxic action by activating or inhibiting enzymes. In addition, chemicals transmitted through food chain have harmed to physiological mechanisms in men.

Carbosulfan is one of the widely used insecticides in agriculture, it was also proposed for treatment against pyrethroid-resistant mosquitoes ${ }^{1}$. It belongs to the carbamates class of insecticides and to carbofuran sulfonylated derivates. It is a systemic insecticide that acts with direct contact or by stomach ingestion. It issued extensively in the United States, Europe, and Tunisia for pest control in a wide range of crops. Carbosulfan toxicological evaluation was compiled by JMPR in $2003^{2}$.

Carbosulfan is normally metabolized by initial oxidation of the sulfur atom and by cleavage of the $\mathrm{N}-\mathrm{S}$ bond. Metabolites were analyzed by Thin Layer Chromatography (TLC) and the principal metabolites were the conjugated 3-keto-7-phenolcarbofuran, 3-ketocarbofuran, and dibutylamine. It has been showed that Carbosulfan was slowly converted into a variety of products in rat stomach. The major products of alteration were carbofuran and biscarbofuran N,N'-disulfide ${ }^{3,4}$.

A considerable number of data has been published on carbamate pesticide toxicity. Few, however, concerned carbosulfan while several studied the effect of carbofuran, a product of degradation of carbosulfan. Exposure to carbofuran markedly suppressed the humoral immune response in mice. This chemical exposure resulted in a decreased plasma cell count in popliteal lymphoid nodes, and a reduction of germinal centers in the spleen $^{5}$. Also, this study reported that a single acute exposure to carbofuran suppressed humoral immune responses in mice. Transient but marked inhibition of plaque forming cell (PFC) response was observed at day 10 after exposure to carbofuran $(0.6 \mathrm{mg} / \mathrm{kg} \text { body weight })^{5}$. In addition, carbofuran exposure causes suppression of bone marrow cellularity and decreased granulocyte-macrophage progenitor cells in C57BL/6 mice with doses as low as $0.3 \mathrm{mg} / \mathrm{kg} / \mathrm{day}$ for $7 \mathrm{days}^{6}$.Carbofuran application inhibits also splenic T cell proliferation and causes a dose-related decrease in thymic cellularity ${ }^{7}$. In an in vivo study, Kubosaki et al., evaluated the immunotoxic effects of carbofuran in rat splenocytes after oral administration ${ }^{8}$. The authors reported a significant reduction in 
a mixed lymphocyte response, $\mathrm{T}$ lymphocyte cytotoxic activity, and natural killer cell activity with the highest test dose. The biochemical mechanism of carbamate pesticides toxicity such as carbofuran, are well-known; they are acting by inhibiting the acetylcholinesterase activity, enzyme preventing the accumulation of the neurotransmitter acetylcholine in the synapses and in the neuromuscular junctions.

Many other studies focused on immunotoxicity of organophosphorus pesticides. In vitro exposure of murine splenocytes to malathion inhibited the proliferative response to mitogen stimulation, while in vivo exposure of peritoneal cells suppressed the respiratory burst activity ${ }^{9}$. Oral administration of malathion caused elevation in macrophages functions ${ }^{9,10}$. Malathion has also been demonstrated to decrease serum immunoglobulin (IgM and $\operatorname{IgG})$ concentrations, and inhibit leukocytes and macrophages migration ${ }^{11}$.

Herein, we investigated the in vivo effects of carbosulfan on hematological parameters, hepatic levels and spleen rat cellular immunity ( $\mathrm{T}$ cell subtypes, mitogen-stimulated proliferation and Th1- and Th2-type cytokines production). Both proliferation and cytokines release are considered to be very relevant to investigate the toxicity towards the immune system. In order, to evaluate the toxicity of carbosulfan, young male Wistar rats, were orally exposed. The parameters were chosen due to their importance as index of hematotoxicity, hepatotoxicity and immunotoxicity caused by chemicals.

\section{Animals}

\section{Methods}

Rats (Wistar, 100-150g of weight and 45 days of age) procured from Tunisian Society of Pharmaceutical Industries, divided into two groups, and housed two per cage in sterile plastic cage. The vivarium was maintained under normal day/night schedule (12 h Light/12 h Dark cycles) at room temperature $25^{\circ} \mathrm{C} \pm 1{ }^{\circ} \mathrm{C}$. Balanced food and water were given to the animals ad libitum. All the procedures were in accordance with Guidelines for Ethical Conduct in the Care and Use of Animals.

\section{Chemical}

Carbosulfan (CB) used for rat gavage was provided by Tunisian Ministry of Agriculture; before use CB was dissolved in corn oil for a final concentration $25 \mathrm{mg} / \mathrm{ml}$.

In all cellular experiments, cells were resuspended in RPMI-1640 medium supplemented with $10 \%$ fetal bovine serum (FBS), 100U/ml penicillin, $100 \mu \mathrm{g} / \mathrm{ml}$ streptomycin and $2 \mathrm{mM}$ glutamine (Invitrogen, Cergy Pontoise, France). Phytohemagglutinin-A (PHA) (Invitrogen, Cergy Pontoise, France) was used for in vitro cell stimulation. Sandwich ELISA kits were used for quantitation of IFN-gamma and IL-4 (Biovendor, Czech Republic).Monoclonal anti-rat antibodies were used for flow cytometry analysis: FITC-CD3, RPE-CD4, FITCCD8-alpha and Isotype control (AbCys, France).Reagents and kits from Biomaghreb Laboratories (Tunis, Tunisia) were used to measure hepatic enzyme levels and renal function.

\section{Treatment schedule}

The rats were randomly divided into two groups of 12 animals each. The first group (control group) received orally $1 \mathrm{ml}$ corn oil via stomach tube daily during 30 days. The second received an amount of $1 \mathrm{ml}$ corn oil containing $25 \mathrm{mg}$ of $\mathrm{CB} / \mathrm{kg}$ of body weight/day. The choice of $\mathrm{CB}$ dose was based on previous experimental assays in our laboratory, which corresponds to an acceptable dose that did not cause any sign of toxicity until the end of the experiments. This dose corresponds to $20 \%$ of DL50 for rat.

\section{Blood collection, body weight, and organ weight}

At day 30 and $2 \mathrm{~h}$ after the last dose, blood was collected from the retro-orbital plexus of each rat using heparinized capillary tubes for determination of the acetylcholinesterase activity and EDTA tubes for hematological, hepatic and renal parameters determination. Rats were then sacrificed by cervical dislocation. Body weight (BW) and organ weight for kidney, liver, spleen and thymus were determined for each animal.

\section{Measurement of hepatic enzyme levels}

The protein content of plasma was spectrophotometrically estimated according to the method of Bradford ${ }^{12}$, using Coomassie protein assay dye and bovine serum albumin as standard. Plasma enzyme activities: Aspartame aminotransferase (AST), Alanin aminotransferase (ALT), Lactate desydrogenase (LDH) and Alkaline phosphatase (ALP) were measured using an auto analyzer.

\section{Renal function}

Renal function was analyzed by determining creatinine ${ }^{13}$, uric acid ${ }^{14}$, and urea ${ }^{15}$ levels in plasma. Samples, standards and controls were each added to $1-\mathrm{mL}$ reaction mixture and read spectrophotomerically at 492,510 , and $340 \mathrm{~nm}$, respectively. Results were expressed in $\mathrm{mg} / \mathrm{L}$. 


\section{Determination of the hematological parameters}

Blood samples were analyzed immediately for hematological parameter using an automatic hematological assay analyzer (BC-2800 VET mindray autohematology analyzor). Routine hematological parameters were assessed : Red Blood Cell (RBC), White Blood Cell (WBC), and Platelet (PLT) counts, Mean Cell Volume (MCV), Mean Corpuscular Hemoglobin (MCH), Mean Corpuscular Hemoglobin Concentration (MCHC), Hemoglobin (Hb), Hematocrite (HCT) levels, and Packed Cell Volume percentage (PCV\%).

\section{Determination of Red Blood Cell-cholinesterase activity}

Acetylcholinesterase (AChE) activity was measured in RBCs collected from rats according to Ellman et al., ${ }^{16}$. Briefly, after collecting $0.5 \mathrm{ml}$ peripheral blood, RBCs were separated by centrifugation and washed three times with normal saline buffer. Then, $100 \mu 1$ of compact RBCs was lysed in distilled water and $100 \mu 1$ of this lysate was incubated with Di-Thio-bis-Nitro-Benzoic acid (containing Quinidine Sulfate as plasma cholinesterase inhibitor and Thiocholine Iodide as substrate) at $37^{\circ} \mathrm{C}$ for $10 \mathrm{~min}$. The reaction was terminated by adding Hyamine (Benzethonium Chloride) at $0.002 \%$, and the absorption was measured by spectrophotometer (Shimadzu, Japon) at $440 \mathrm{~nm}$ wavelength. The AChE activity of the blood samples was calculated by multiplying the sample optical density (OD) by the converting factor $17.68 \mathrm{nmol} / \mathrm{min} / 1$.

\section{Preparation of spleen cells suspension}

The spleen was transferred to a Petri dish containing50ml of complete Media. The spleen was teased between two frosted slides and the tissue dispersion was centrifuged at $1200 \mathrm{rpm}$ at $4{ }^{\circ} \mathrm{C}$ for $10 \mathrm{~min}$. The supernatant was discarded and the pellet was resuspended in $3 \mathrm{ml}$ of $\mathrm{RBC}$ lysing containing $0.83 \% \mathrm{NH}_{4} \mathrm{Cl}$ in $100 \mathrm{mM}$ Tris buffer ( $\mathrm{pH}$ 7.4) and kept at room temperature for $3 \mathrm{~min}$. The cells were washed three times with the RPMI-1640 and finally suspended in $1 \mathrm{ml}$ of complete media. Viability of cells was performed using the trypan blue exclusion method ${ }^{17}$.

\section{Lymphocyte proliferation}

Lymphocyte proliferation was performed in triplicates as previously described ${ }^{18}$. Briefly, cells were cultured in 96-well plates in complete media at $2 \times 10^{6}$ cells $/ \mathrm{ml}$ in a final volume of $200 \mu \mathrm{l}$ and incubated with or without PHA at a final concentration of $5 \mu \mathrm{g} / \mathrm{ml}$ during 48 hours at $37^{\circ} \mathrm{C}$ in a $5 \% \mathrm{CO}_{2}$ humidified atmosphere. Cell proliferation was determined by the uptake of $(3 \mathrm{H})$ thymidine (Amersham, Saclay, France), measured 18 hours after adding $0.4 \mu \mathrm{Ci} /$ well. Cells were harvested and the radioactivity was counted in a Micro Beta 2 Plate Counter (PerkinElmer). Results were expressed as a proliferation index (PI): mean counts of triplicates in PHAstimulated cultures /mean counts of triplicates in unstimulated cultures.

\section{Spleen cell subtyping}

Spleen cell phenotyping was done as previously described ${ }^{8}$. Splenocytes cell suspension in RPMI$1640\left(1 \times 10^{6}\right.$ cells $\left./ \mathrm{ml}\right)$ was washed with PBS and incubated with anti-CD3, anti-CD4 and anti-CD8 antibodies according to manufacturer's instruction. Cell subtypes were determined using BD FACS Vantage ${ }^{\mathrm{TM}}$ flow cytometer.

\section{Cytokine Production}

For IL-4 and IFN- $\gamma$ detection, supernatants of cell culture were collected after $48 \mathrm{~h}$, centrifuged and kept at $-80^{\circ} \mathrm{C}$ until use. Capture enzyme-linked immunosorbent assay (ELISA) was used for cytokine quantification according to the manufacturer's instructions ${ }^{19}$.

\section{Statistical analysis}

Data were statistically analyzed using Student " $t$ " test to determine significant differences between different groups. $\mathrm{P}$ values less than 0.05 were considered significant. The values are expressed as means $\pm \mathrm{SD}$.

\section{Clinical signs, body weight and organ weight}

\section{Results}

The administered dose of $\mathrm{CB}$ showed no mortality in the treated group. No significant body weight differences were recorded in treated group of animals (Fig. 1). However, we noted that control rats increased their weight by $30 \%$ in one month while CB exposed rats did not. As shown in Table 1, we found a significant increase in liver and kidney weight in treated group of rats and a significant decrease of thymus and spleen weight. Interestingly, CB caused a significant decrease of the spleen cellularity as the count of the cells was $334.03 \pm 38.8 \times 10^{6}$ for the control group versus $222.32 \pm 12.3 \times 10^{6}$ for the treated group $(\mathrm{P} \leq 0.05)$. 


\section{Blood biochemistry}

\subsection{Liver enzyme levels}

Total protein, AST, ALT, LDH and ALP are indicators of hepatic function. As is shown in Table 2, CB caused a significant decrease in total protein levels and a significant increase in ALT and ALP levels.

\subsection{Renal Function}

Treatment of rats with $25 \mathrm{mg}$ of $\mathrm{CB} / \mathrm{kg}$ body weight for 30 days caused a marked elevation in blood creatinine level $(\mathrm{P} \leq 0.01)$. The data indicated also a significant elevation in blood urea level $(\mathrm{P} \leq 0.05)$ in $\mathrm{CB}$ group and a slight and non significant increase in uric acid level in CB group. Our data also show a significant increase in kidney proteins level in CB group when compared with control group (Table 2).

\section{Hematological and immunological toxicity}

3.1. Effects on peripheral cells

\subsubsection{RBC-Cholinesterase activity}

Carbosulfan showed more than 29\% RBC-Cholinesterase inhibition between the treated and control group $(7.028 \pm 2.399 \mathrm{nmol} / \mathrm{mg} / \mathrm{mn}$ versus $10.009 \pm 5.05 \mathrm{nmol} / \mathrm{mg} / \mathrm{mn})(\mathrm{P} \leq 0.05)$ (Fig.2).

\subsubsection{Hematological parameters}

Administration of $\mathrm{CB}$ does show an increase in hematological RBC values (Table 2). So, CB significantly increased WBC counts compared to control group (Table 3). Interestingly, such increase did not concern lymphocytes or monocytes. The counts of the latter cells were significantly reduced in CB exposed rats. Following the subchronic exposure to $\mathrm{CB}$, there was a significant increase in hematological values of HGB, HCT and PLT in treated rats (Table 3).

\subsection{Effect on spleen cellularity}

\subsubsection{Quantitative assay: Spleen $T$ cell subtyping}

No significant change in the percentage of splenic CD4 T cells and a significant decrease in CD8 T cells were noted in treated rats compared to control group (Fig.3).

\subsubsection{Qualitative assay}

\subsubsection{Proliferative response to $\mathrm{PHA}$}

While carbosulfan did not display any significant effect on the spleen CD4 $\mathrm{T}$ cell subtyping, it significantly suppressed the proliferative response of splenocytes to mitogens (Fig.4).

\subsubsection{Cytokine production}

CB decreased significantly $(\mathrm{P}<0.05)$ the production of IFN-gamma (Fig.5A) and IL-4 (Fig.5B) production in response to PHA (as mitogen) in CB treated rats compared to controls.

\section{Discussion}

It is well known that heavy pesticides are widely used in agriculture. Some of them can cause biological and histological disorders. Humans are exposed to these pesticides from many sources, including contaminated soil, food and water.

Carbosulfan, as a carbamate insecticide, has been widely used in industrial agriculture worldwide and could be potentially an exposure risk to the workers in the field and to the public ${ }^{20}$. Toxic effects of carbamates occur through acetylcholinesterase inhibition. Thus, symptoms of exposure are similar to those of organophosphorus ${ }^{21}$. Carbamates are not broad spectrum pesticides, but they have been widely used because of their low persistence in the environment. Carbaryl, carbofuran, aminocarb, and aldicarb are examples of generally used chemicals within this group. Carbosulfan (CB) has been widely used against pyrethroid resistant mosquitos and seems to be very effective ${ }^{22}$.

\section{Hepatotoxicity and nephrotoxicity of carbosulfan}

To evaluate CB hepatotoxicity, liver enzymes (AST, ALT, LDH and ALP) were used as biomarkers. Few studies about CB toxicity in animals and humans are available even with the wild use of CB. Thus, we were unable to compare our results with previous ones. Our results were therefore compared to those studying toxic effect of other carbamate insecticides. Our data showed that the CB-treated animals exhibited significantly lower liver protein level than the control animals. This carbamate pesticide possibly alters protein and free amino acid metabolism and their synthesis in the liver ${ }^{22}$. Four serum hepatic markers enzymes (ALT, AST, ALP and LDH) were evaluated for hepatotoxicity. According to the found results, CB caused a significant 
increase in the ALT and ALP activities, and a slight increase in AST and LDH activities in treated rats compared with controls. Ours results corroborate with those found by Kseerasagar and Kaliwall ${ }^{23}$, they indicate that carbosulfan administered orally at doses of $12,24,36$ and $48 \mathrm{mg} / \mathrm{kg} / \mathrm{d}$ to albino mice for 30 days can increase ASAT and ALAT levels. The elevation of such enzymes is a marker of liver damage ${ }^{23}$.Our data corroborate those obtained with carbamate insecticides showing an increase in the mammalian enzymatic activities of ALT, AST, ALP and LDH ${ }^{22}$. According to Kseerasagar ${ }^{23}$, the increase in ALT, AST, ALP and LDH enzymatic serum activity results in reversible and irreversible alteration on hepatic cellular membrane permeability. Interestingly, other insecticides such asorganophosphorus insecticides can elevate the enzymatic activities of ALP, ALT, AST, and LDH ${ }^{22}$. Malathion also raises the ALT and AST levels in rats ${ }^{23}$. The rise in AST and ALT levels in the liver of rat could be due to hepatotoxicity causing permeability alterations and leakage of lysosomal enzymes causing enhanced release of enzymes ${ }^{23}$.Also, effect of carbosulfan could take place via the absorption, distribution or elimination rates. In addition, induction and inhibition of the liver microsomal enzymes (cytochrom P450) could also play significant roles in pesticides toxicity ${ }^{24}$.

Recent observations indicate that long-term exposure to highest dose $(200 \mathrm{mg} / \mathrm{kg} \mathrm{b.w.)} \mathrm{of} \mathrm{hexachloro-}$ 1:3-butadienemay increase risks of subclinical nephropathy as indicated by the elevation of plasma creatinine, uric acid and urea levels ${ }^{25}$. Clinical manifestations of renal impairment do not become evident until more than $50 \%$ of the nephrons are destroyed ${ }^{26}$. Thus, we evaluated some parameters related to the renal function after to subchronic exposure to $\mathrm{CB}$. Our data showed that subchronic exposure to $\mathrm{CB}$ caused nephrotic damage demonstrated by the increased of plasma creatinine and urea levels. In addition, a non significant increase in uric acid level was also obtained in CB group. Urea is the first acute renal marker, which increases when the kidney suffers any kind of injury. Creatinine is, however, the most trustable renal marker. Its increase occurs only when the majority of renal function is lost ${ }^{27}$. However, uric acid (the final product of purine nucleotides metabolism) is a very important aqueous antioxidant accounting for up to $60 \%$ of plasma antioxidative capacity ${ }^{28}$. Moreover, CB increased PTL counts leading to an enhancement of the risk of thrombosis by forming platelet aggregates causing vascular obstruction. While the liver is reported as the major target organ on repeated administration of $\mathrm{CB}$, the kidney suffers the effects of biotransformation and subsequent excretion of $\mathrm{CB}$ may induce severe nephrotoxicity ${ }^{23,29}$. Toxic effects of $\mathrm{CB}$ in the kidney of both humans and experimental animals begin with changes in glomerular function, followed by acute morphologic changes that may slowly progress to a chronic irreversible nephropathy. The initial morphological changes include formation of $\mathrm{CB}$ protein complexes called nuclear inclusion bodies and ultrastructural changes in cellular organelles, especially mitochondria.

From the foregoing study, it can be concluded that carbosulfan treatment leads to enhanced toxicity by altering hepatic and nephrotic function in rats after 30 days orally exposure.

\section{Hematological and immunological toxicity of carbosulfan}

Even with the over use of CB, few data have been obtained about its influence on the immune system. Moreover, sub chronic effect of carbosulfan on the immune system has not been clearly defined ${ }^{30}$. An extensive and systemic study on dose time relationship in different experimental animals appears to be essential to establish the definitive immunomodulatory role of carbosulfan keeping this in view. In few studies conducted in mouse model with the principal metabolite of carbosulfan (carbofuran) an immunosuppressive effect was showed. Carbofuran suppresses proliferation of $\mathrm{T}$ cells ${ }^{31}$. We thus focused on the effects of carbosulfan on Tcell-mediated immune response (CMIR): $\mathrm{T}$ cell subtyping, cell proliferation and cytokine production in splenocytes.

First, we demonstrated that subchronic exposure to $\mathrm{CB}$ at $25 \mathrm{mg} / \mathrm{kg}$ per day caused changes in rat physiological system. In fact, this dose can inhibit drastically the RBC- cholinesterase activity (Fig. 2). AChE facilitates hydrolysis of acetylcholine at cholinergic nerve terminals. Inhibition of AChE results in accumulation of acetylcholine, which is a key mechanism in toxicity of organophosphorus and carbamate pesticides ${ }^{32}$. AChE activity has been shown to be reduced in brain and liver of rats intoxicated with carbofuran ${ }^{33}$.

Our results also demonstrated that $\mathrm{CB}$ caused an alteration in hematological constituents. On one hand, we observed a non significant decrease in treated rat RBC level. $\mathrm{CB}$ can impair RBC production through the destruction of erythrocytes. This hypothesis is corroborated by experiments in rabbits treated with zinc ethylenebis-dithiocarbamate (zineb). After 90 days of treatment, a marked decline in erythrocyte counts was observed ${ }^{34}$. This disturbance of biochemical and physiological RBC function could be due to lipid peroxidation ${ }^{35}$. In addition, oxidative damage in RBC may results from the presence of polyunsaturated fatty acid, heme iron and oxygen ${ }^{36}$. Moreover, Muthuviveganandavel et al. (2008) found that red blood cells count significantly decreased in rats treated with 5 and $25 \mathrm{mM}$ Carbendazim, a carbamate pesticide ${ }^{37}$. Such results are consistent with ours. In an extensive investigation made by Gupta (1994), effects of carbofuran with multiple intraperitoneal doses in mice $(0.25 \mathrm{mg} / \mathrm{Kg})$ on a variety of hematological parameters (RBC, WBC, MC, MCH, MCHC, PLT counts, HGB and HCT levels) were investigated ${ }^{38}$. Carbofuran intoxication caused a significant increase in HGB content, WBC count, platelets and HCT levels. Similar results were obtained in our study with 
carbosulfan. In other study, as for carbosulfan treatment, there were no significant changes in hematological findings after 90 day of exposure to mice ${ }^{39}$. Moreover, severe oxidative stress can lead to haemolysis. In principle, the erythrocyte is very sensitive to peroxidative reactions. Under normal conditions, erythrocyte is very well protected against peroxidative reactions by the presence of catalase and glutathione. This balance, however, can be disturbed by different chemicals. Oxidative damage can result indirect injury to the cell membrane due to lipid peroxidation and bring about changes in membrane proteins and consequently, the permeability of such membranes of any erythrocyte ${ }^{40,41}$.

The intoxication increased total WBC and prolonged clotting time ${ }^{38}$. The increase of WBC values could be normal reaction of white cells against any foreign substance. Leukocyte increase demonstrated the guard of rat immune system after exposing to CB. The increase of WBC values seems to concern particularly neutrophils and could result from an inflammation caused by CB general toxicity ${ }^{42}$. Also, leukocytosis detected in rats exposed to carbosulfan pesticide may be due to release of catecholamine as a stress hormone, which causes demargination of neutrophils, is often accompanied by lymphocytosis and sometimes by monocytosis and eosinophilia ${ }^{41,43}$.

After 30 days of oral carbosulfan administration, we found a significant decrease in spleen cellularity with a marked change in CD8 T cells. Ours results corroborate with the data reported on the immunotoxicity of carbaryl (a carbamate with low cholinergic toxicity), Casale et al., in 1993 found that a significant inhibition of cell subtyping and $\mathrm{T}$ cell proliferation ${ }^{31}$.Interestingly, subchronic exposure to $\mathrm{CB}$ leads to an overall suppression of T cell activity. Dhasarathan et al., (2010), show that carbosulfan can suppress humoral and T cell mediated immune response in mice ${ }^{24}$. This suppression was manifested by the inhibition of the lymphocyte proliferative responses to PHA. Such effect on T cell proliferation, which is one of the most characteristic responses of $\mathrm{T}$ cells to mitogenic stimulation, seems to be related to an effect of $\mathrm{CB}$ on activation and differentiation of $\mathrm{T}$ lymphocytes. The decrease in $\mathrm{T}$ cell proliferation explains the decrease in cellularity and weight of primary and secondary lymphoid organs. The effect of $\mathrm{CB}$ on cellular immune functions was further supported by the inhibition of cytokine release. As known, activated $\mathrm{T}$ cells release cytokines to regulate and mediate diverse immune responses ${ }^{44}$. Th1 cells express IL-2 and IFN-gamma, are mainly responsible for phagocyte-mediated host defense and constitute the main effectors of cell-mediated immunity, delayed-type hypersensitivity reactions and chronic inflammation. Th2 cells express IL-4 and IL-10 and promote the humoral immunity, allergic reactions and the recruitment of eosinophils ${ }^{45}$. Our data showed a significant decrease in production of Th1 and Th2 cytokines confirming that the effects of $\mathrm{CB}$ are related to both humoral and cellular immunity. Our results are in agreement with previous studies concerned with other carbamate pesticides. Carbaryl inhibited humoral immunity in mice ${ }^{31}$. In vitro, carbaryl impaired the immune function of splenocytes ${ }^{46}$. Carbofuran suppressed both humoral ${ }^{47,48}$ and cellular immunity and inhibited the expression of complement activity when added to human serum ${ }^{31}$. Animals exposed to aldicarb or ethyl carbamate which is a suffered from lowered humoral immune response ${ }^{49}$.

Several possible mechanisms may explain the inhibitory effects of carbosulfan on lymphocytes. One possible explanation is the reduction of IL-2 secretion by PHA-stimulated lymphocytes, knowing that IL-2 is a potent $\mathrm{T}$ lymphocyte activator. It is also possible that carbosulfan may act directly on $\mathrm{T}$ lymphocytes, by activating or inhibiting cell proliferation. It may induce the expression of stress signals at the surface of the cells and later cells died by apoptosis rather than proliferating upon stimulation. The decrease of cytokines levels in the culture supernatants may be due to diminution of number of cells or to a simple blockage of the system of expression. Several studies showed that chronic exposure to pesticides suppresses cellular immune response, which is associated with increased excess of free radical generation ${ }^{6}$. Therefore, pesticides induced oxidative stress which may contribute to its immunotoxicity as previously reported ${ }^{50}$. Free radicals are known to attack unsaturated fatty acid side chains of phospholipids, causing a substantial decrease of these cells membrane components. This effect leads to reduced membrane fluidity ${ }^{50}$. In physiological conditions the process underlying lymphocyte interaction with antigens or with other cell subsets requires the integrity of cell membrane. It is possible that free oxygen radicals generated by $\mathrm{CB}$ could inhibit $\mathrm{T}$ cell function via membrane lipids peroxidation ${ }^{51}$, Sarsat et al., demonstrated since 1993 that in the cell system, treatment of lymphocytes with autologous PMN-derived chloramines induced a profound decrease in their total and reduced glutathione (GSH) content ${ }^{52}$. The authors concluded that lymphocytes may play a defensive role against phagocyte-derived oxidative stress by scavenging chloramines, and as this effect, which is mediated by GSH, affects lymphocyte proliferative responses, it may help to elucidate the still obscure mechanisms of oxidative stress associated immunodeficiency. Thus, the susceptibility of $\mathrm{T}$ cells to lipid peroxidation may be the result of lower levels of intracellular antioxidants, such as reduced glutathione (GSH) and it is important in lymphocyte activation and proliferation. Altogether, these data confirm the hypothesis of immune-toxicity induced by oxidative stress caused by $\mathrm{CB}$. 


\section{Conclusions}

In conclusion, the present study shows that carbosulfan at the dose of $25 \mathrm{mg} / \mathrm{kg}$ has an inhibitory effect on the cell-mediated immunity. Our data indicate that carbosulfan can decrease spleen cell activation and differentiation. This dose of $\mathrm{CB}$ seems to be an appropriate dosage for assessment of NOAEL, which is recommended by WHO experts committee for immunotoxicological considerations. It is apparent that complete understanding of toxicity of carbosulfan is necessary to study human health hazards and to establish guidelines for setting no observable adverse effect level (NOAEL) it is emphasized that threshold level of the chemical below which no effect would be seen depends on the method of testing for immune response, animals species, endocrine and nutritional status of the host and type of antigen against which the responses are studied.

It is clear from the present study that the immune system may be a sensitive target for carbosulfan for which the exact molecular target or mechanism of immunotoxicity are not known and indeed for many compounds there are probably multiple targets and mechanism of action ${ }^{53}$. The explanation for immunosuppressive effect of carbosulfan therefore, may be at many levels. Hence, Immunosuppression by carbosulfan may be a consequence of toxic chemical stress induced cholinergic stimulation and its effects on immune cells (Lymphocyte) function. Carbosulfan may also influence physiological and pathological conditions, hormonal functions, nutritional/ oxidative stress and hepatic metabolism ${ }^{54}$. It may also act directly or indirectly on lymphoidal cells, immunoglobulin metabolism, T/B cell macrophage cooperation and macromolecular biosynthesis.

\section{Declaration of interest}

The authors report no conflicts of interest. The authors alone are responsible for the content and writing of the paper.

\section{References}

[1]. P. Guillet, R. N'Guessan, F. Darriet, M. Traore-Lamizana, F. Chanre, and P. Carnevale, Combined pyrethroid and carbamate twoin-one treated mosquito nets: field efficacy against pyrethroid-resistant Anopheles gambiaeand Culexquinquefasciatus, Med. Vet. Entomol.15, 2001, 102-112.

[2]. FAO/WHO, Pesticide residues in food. Toxicological evaluations, World Health Organization, Geneva.http//www.who.int/pcs/jmpr/2003.htm.

[3]. P.J. Marsden, E. Kuwano, and T.R. Fukuto, Metabolism of carbosulfan [2,3-dihydro-2,2-dimethylbenzofuran-7-yl (di-nbutylaminothio) methylcarbamate] in the rat and house fly, Pestic. Biochem.Physiol, 18, 1982, 38-48.

[4]. K. Abass, P. Reponen, S. Mattila, and O. Pelkonen, Metabolism of carbosulfan. I. Species differences in the in vitro biotransformation by mammalian hepatic microsomes including human, Chem. Biol. Interact, 181, 2009, $210-219$.

[5]. D. Flipo, J. Bernie, D. Girard, K. Krzystyniak, and M. Fournier, Combined effects of selected insecticides on humoral immune response in mice, Int. J. Immunopharmac. 14, 1992, 747-752.

[6]. S.D. Jeon, J.S. Lim, and C.K. Moon, Carbofuran suppresses T-cell-mediated immune responses by the suppression of T-cell responsiveness, the differential inhibition of cytokine production, and NO production in macrophages, Toxicology Letters, 119, 2001, 143-155.

[7] . G.J. Prud'homme, C.A. Piccirillo, The inhibitory effects of tranforming growth factor beta-1 in autoimmue diseases, $J$. Autoimmun. 14, 2000, 23-42.

[8]. A. Kubosaki, M. Aihara, B.J. Park, Y. Sugiura, M. Shibutani, M. Hirose, Y. Suzuki, K. Takatori, and Y. Sugita-Konishi, Immunotoxicity of nivalenol after subchronic dietary exposure to rats, Food Chem. Toxicol. 46, 2008, 253-258.

[9]. K. Rodgers, and S. Xiong, Effect of acute administration of malathion by oral and dermal routes on serum histamine levels, Int. J. Immunopharmacol, 19, 1997a, 437-41.

[10]. K. Rodgers, and S. Xiong, Contribution of inflammatory mast cell mediators to alterations in macrophage function after malathion administration, Int. J. Immunopharmacol, 19, 1997b, 149-56.

[11]. B.D. Banerjee, S.T.Pasha, Q.Z. Hussain, B.C. Koner, and A. Ray A, comparative evaluation of immunotoxicity of malathion after subchronic exposure in experimental animals, Indian J. Exp. Biol, 36, 1998, 273-82.

[12]. M. Bradford, A rapid and sensitive for the quantification of microgram quantities of protein utilizing the principle of protein-dye binding, Anal Biochem. 72, 1976, 248-51.

[13]. Larsen K., Clin. Chim.Acta 66, 209 (1972).

[14]. P. Fossati, L. Prencipe, and G. Berti, Use of 3, 5-dichloro-2- hydroxybenzenesulfonic acid/4-aminophenazone chromogenic system in direct enzyme asay of uric acid in serum and urine, Clin. Chem, 26, 1980, 227-231.

[15]. J.K. Fawcett, A rapid and precise method for the determination of urea, J. Clin. Pathol.13, 1960, 156-9.

[16]. G.L. Ellman, K.D. Courtney, V.J. Andres, and R.M. Featherstone, A new and rapid colorimetric determination of acethylcholinesterase activity, Biochem. Phamacol. 7, 1961, 88-95.

[17] N. Abuharfeil, E. Sarsour, and M. Hassuneh, The effect of sodium nitrite on some parameters of the immune system, Food Chem. Toxicol. 39, 2001, 119-124.

[18] T. Mosmann, Rapid colorimetric assay for cellular growth and survival: application to proliferation and cytotoxicity assays, $J$. Immunol. Methods, 65, 1983, 55-63.

[19] K.C. Zheng, M. Ariizumi, H. Todoriki, and M. Shinjo, Cytokine production by splenocytes and thymocytes in mice after intranasal exposure to toluene diisocyanate, J. Occup. Health .40, 1998, 279-284.

[20] WHO, Carbosulfan, Environmental Health Criteria, International Program on Chemical Safety, United Nations Environmental Program. World Health Organization, Geneva, Switzerland, 1998.

[21] K. Rodgers, Immunotoxicity of Pesticides. In: Handbook of Pesticide Toxicology. Principles 2001.

[22] S.Ncibi, M.B. Othman, A. Akacha, M.N. Krifi, and L. Zourgi, Opuntiaficusindica extract protects against chlorpyrifos-induced damage on mice liver, Food Chem. Toxicol, 46, 2008, 797-802.

[23]. R. L. Ksheerasagar, and B. B. Kaliwal, Carbosulfan Induced Renal Toxicity in Albino Mice, J.Exp. Sc,1, 2010, 17-22.

[24] P. Dhasarathan, P. A. Pathrose, and S. Paulsi, Immunomodulation by carbosulfan following sub chronic exposure in Swiss albino mice.J. Biosci. Res. 1, 2010, 130-136. 
[25] A. Trevisan, M. Giraldo, M. Borella,S. Bottegal, and A. Fabrello, Tubular segment-specific biomarkers of nephrotoxicity in the rat, Toxicol. Let.124, 2001, 113-120.

[26]. N. Choudhary, M. Sharma, P. Verma, and S.C. Joshi, Hepato and nephrotoxicity in rat exposed to endosulfan, J. Environ. Biol. 24, 2003, 305-8.

[27] F.E. Uboh, E.N. Asuquo, and M.U. Eteng, Endosulfan-induced hepatotoxicity is route of exposure independent in rats, Toxicol. Ind. Health. 27, 2011, 483-488.

[28]. B. Ames, R. Cathcart, N. Schwiers, and P. Hochstein, Uric acid provides an antioxidant defense in humans against oxidant- and radical-caused aging and cancer: A hypothesis, Proc. Natl. Acad. Sci. USA, 78, 1981, 6858-62.

[29]. S. Ozden, and B. Alpertunga,Effects of methiocarb on lipid peroxidation and glutathione level in rat tissues, Drug Chem.Toxicol,33, 2010, 50-4.

[30]. A.J.A. Ranjithsingh, R. Sornaraj, and P. Dhasarathan, Bacteriological indicators in fish exposed to pesticides. Bull Environ, Contam. Toxicol.70, 2003, 85-89.

[31]. G.P. Casale, J.L. Vennerstrom, S. Bavari, and T.L. Wang, Inhibition of interleukin 2 driven proliferation of mouse CTLL2 cells, by selected carbamate and organophosphate insecticides and congeners of carbaryl, ImmunopharmacolImmunotoxicol. 15, 1993, 199-215.

[32]. L. Guilhermino, L. Celest, A.P. Carvalho, and A.M. Soares, Inhibition of acetylcholinesterase activity as effect criterion in acute tests with juvenile Daphniamagna, Chemosphere, 32,1996, 727-38.

[33]. M. Kaur, and R. Sandhir, Comparative effects of acute and chronic carbofuran exposure on oxidative stress and drug-metabolizing enzymes in liver, Drug Chem. Toxicol. 29, 2006, 415-421.

[34]. C. Nebbia, M. Dacasto, F. Valenza, E. Burdino, G. Ugazio, and J. Fink-Gremmels, Effects of the subchronic administration of zinc ethylene-bis-dithiocarbamate (zineb) to rabbits, Vet. Hum. Toxicol, 37, 1995, 137-42.

[35]. M. Akhgari, M. Abdollahi, A. Kebryaeezadeh, R. Hosseini, and O. Sabzevari, Biochemical evidence for free radical-induced lipid peroxidation as a mechanism for subchronic toxicity of malathion in blood and liver of rats, Hum. Exp. Toxicol. 22, 2003, 205-211.

[36]. M. Kale, N. Rathore, S. John, and D. Bhatnagar, Lipid peroxidative damage on pyrethroid exposure and alterations in antioxidant status in rat erythrocytes: a possible involvement of reactive oxygen species, Toxicol. Lett, 105, 1999, $197-205$.

[37]. V. Muthuviveganandavel, P. Muthuraman, S. Muthu, and K. Srikumar, Toxic effects of carbendazim at low dose levels in male rats, J. Toxicol. Sci. 33, 2008, 25-30.

[38]. R.C. Gupta, Carbofuran Toxicity, J. of Toxicol. andEnv. Health.43, 1994, 383-418.

[39]. A.A. El-Kashory, and M.M. El-Said, Study of aldosterone level, electrolytic balance and haematological changes following exposure to low doses of profenofos, carbosulfan and imidaclopride in male albino rats, J. Egypt. Vet. Med. Assoc, 61, $2001,4$.

[40]. B.M. Bush, Electrolytes and metals. In "Interpretation of laboratory results for small animal clinicians, Oxford Blackwell Scientific Publications. 1991,350-383.

[41]. M.A. Kandil, A.A. El-Kashoury, M.M. El-Said, and M.A. El-Herrawy, Interactive effects of imidacloprid, profenofos and carbosulfan at low concentrations on homeostasis and haematological indices in male albino rats, J. Egypt. Soc. Toxicol, 35, 2006, $69-78$.

[42]. T. Vial, B. Nicolas. and J. Descotes, Clinical immunotoxicity of pwesticides, J. Toxicol. Environ. Health.48, 1996, 215.

[43]. N.C. Jain, Essentials of Veterinary Hematology, Lea \&Febiger, Philadelphia, pp. 1993, 159-295.

[44]. K. Arai, F. Lee, A. Miyajima, S. Miyatake, N. Arai, and T. Yokota, Cytokines: co-ordinators of immune and inflammatory responses, Ann. Rev. Biochem. 59, 1990, 783-836.

[45]. R. Stout, and K. Bottomly, Antigen-specific activation of effector macrophages by interferon-gamma producing (Th1) T-cell clones: failure of IL-4 producing (Th2) T-cell colones to activate effector functions in macrophages, J. Immunol. 142, 1989, 760765.

[46]. K. Rodgers, Immunotoxicity of pesticides. In: Experimental immunotoxicology, R.J. Smialowicz, and M.P.Holsapple, (Eds.), (CRC Press., New York, 1996), 245-63.

[47]. M. Fournier, G.Chevalier, D. Nadeau, B. Trotter, and K. Krzystyniak, Virus-pesticide interactions with murine cellular immunity after sublethal exposure to dieldrin and aminocarb, J. Toxicol. Environ. Health, 1988, 1103-18.

[48]. R. Khurana, S. K. Mahipal, and R. S. Chauhan, Effect of carbofuran on cell mediated immunity in sheep, Indian J. Toxicol. 5(2), 1998,1-6.

[49]. S.W. Cha, M.H. Lee, K.H. Kim, E.J. Kim, S.S. Han., and T.C. Leong, Role of corticosterone in ethyl carbamate induced suppression of antibody response to sheep red blood cells in female BALB/C mice, The Toxicologist. 54, $2000,161$.

[50]. M.C. Caroleo, V. Rispoli, M. Arbitrio, C. Strongoli, G. Rainaldi, D. Rotiroti, and G. Nistico, Chronic administration of paraquat produces immunosuppression of T lymphocytes and astrocytosis in rats, Toxic Subst. Mech. 15, 1996, $183-194$.

[51]. L.K.S. Chauhan, N. Pant, S.K. Gupta, and S.P. Srivastava, Induction of chromosome aberrations, micronucleus formation and sperm abnormalities in mouse following carbofuran exposure, Mutat. Res., 465, 2000, 123-129.

[52]. V.W. Sarsat, A.T. Nguyen, and D. Latscha, Immunomodulatory role of phagocyte derived chloramines involving lymphocyte glutathione, Mediators Inflamm, 2, 1993, 235-41.

[53]. G. Dolapsakis, I.G. Vlachonikolus, C. Varveris, and A.M. Tsatsakis, Mammographic findings and occupational exposure to pesticides currently in use on crate, Env. J. Cancer.37, 2001, 1531-36.

[54]. A.B. Gokhale, A.S. Damre, and M.N. Saraf, Investigations into the immunomodulatory activity of Argyreiaspeciosa, J. Ethnopharmacol. 84, 2003, 109-114. 


\section{Figures}

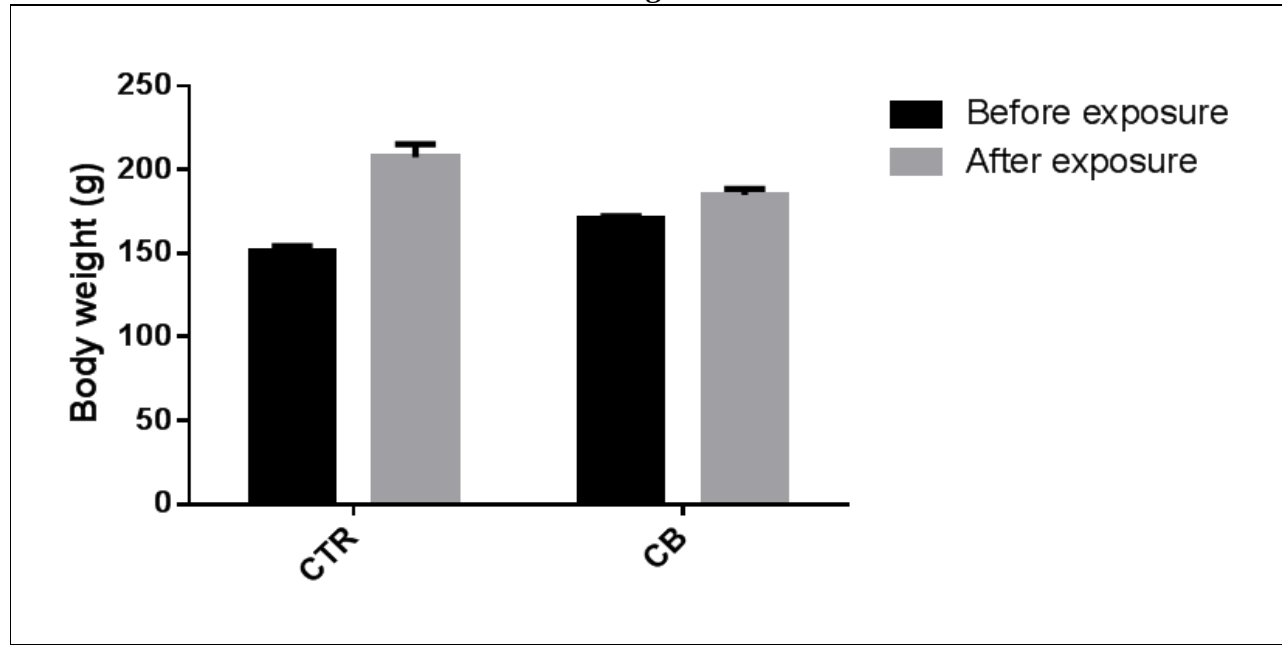

Figure 1: Effect of subchronic exposure to Carbosulfan on control and treated rat body weight before and after treatment.

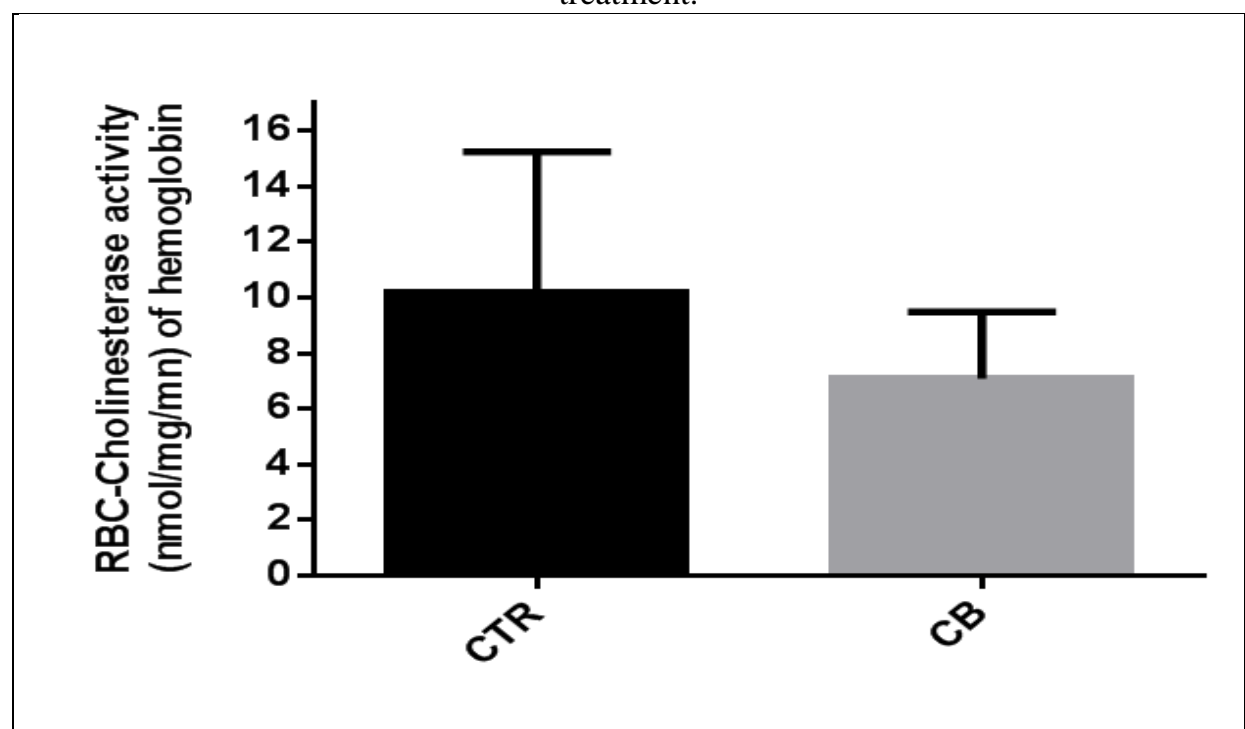

Figure 2: Effect of carbosulfan after subchronic treatment on RBC-cholinesterase activity.

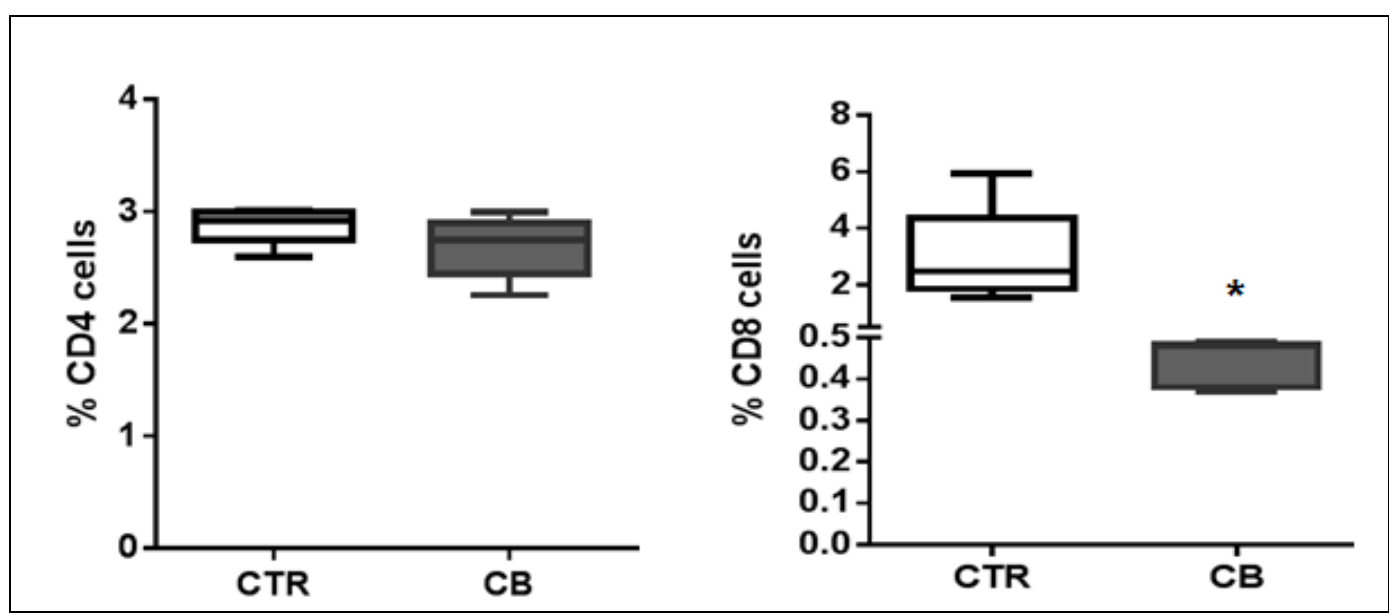

Figure 3: FACS analysis of rat spleen T cells subtypes after subchronic exposure to carbosulfan: Percentage of CD4 and CD8 T cells.

$* p<0.05$ carbosulfan group vs. control group 


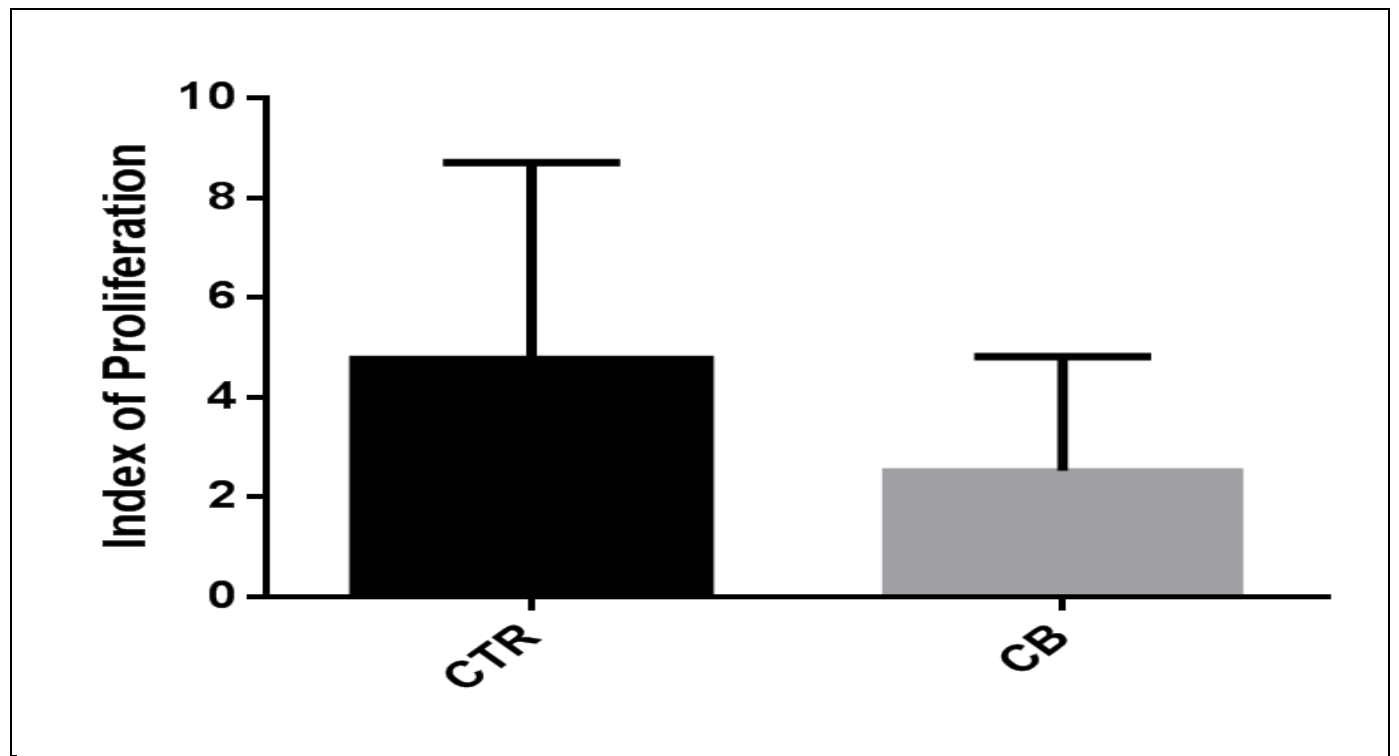

Figure 4: Effects of subchronic exposure to carbosulfan on rat immune cells proliferation. Data are expressed as index of proliferation: mean counts of triplicates in PHA-stimulated cultures /mean counts of triplicates in unstimulated cultures.

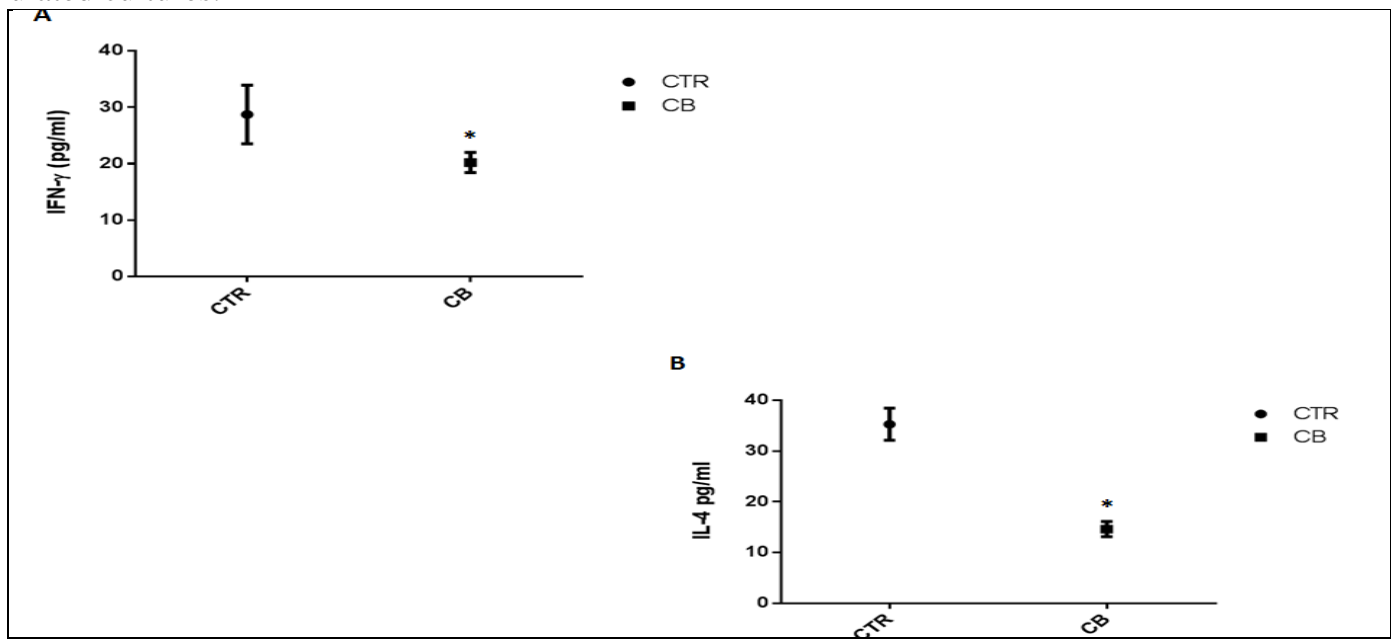

Figure 5: Effects of subchronic exposure to carbosulfan on cytokine production (IFN- $\gamma$ and IL-4) by rat spleen cells. (A) IFN- $\gamma$ production in $\mathrm{pg} / \mathrm{ml}$ (B) IL-4 production in $\mathrm{pg} / \mathrm{ml}$.

$* p<0.05$ carbosulfan group vs. control group

\section{Tables}

Table 1: Effect of subchronic exposure to Carbosulfan on rat organs weight (Mean $\pm \mathrm{SD})$.

\begin{tabular}{|l|c|c|}
\hline & CTR & CB \\
\hline Spleen & $0.626 \pm 0.06$ & $0.47 \pm 0.03^{*}$ \\
\hline Thymus & $0.38 \pm 0.03$ & $0.24 \pm 0.02^{*}$ \\
\hline Liver & $6.89 \pm 0.41$ & $9.06 \pm 0.22^{*}$ \\
\hline Kidney & $0.65 \pm 0.033$ & $0.96 \pm 0.23^{*}$ \\
\hline
\end{tabular}

$C T R$ : control group ; $C B$ : treated group with carbosulfan

*P $<0.05$ versus control group 
Table 2: Hepatic and kidney markers of damage in male rats treated with $\mathrm{CB}(\mathrm{Mean} \pm \mathrm{SD})$.

\begin{tabular}{|l|c|c|}
\hline \multicolumn{2}{|c|}{ CTR } & CB \\
\hline Hepatic markers & \multicolumn{2}{|c|}{} \\
\hline Hepatic Protein (g/100g) & $0.434 \pm 0,05$ & $0.318 \pm 0,01^{*}$ \\
\hline AST (U/L) & $85.7 \pm 6,43$ & $92.5 \pm 5.44$ \\
\hline ALT (U/L) & $40.9 \pm 5.96$ & $56.5 \pm 5.73^{*}$ \\
\hline LDH (U/L) & $1014.3 \pm 58.8$ & $264.802 \pm 19,864^{*}$ \\
\hline ALP (U/L) & $222.416 \pm 15.608$ & \\
\hline Kidney markers & & $4.42 \pm 0.23^{* *}$ \\
\hline Kidney Protein (g/100g) & $3.72 \pm 0.28$ & $6.55 \pm 0.03^{*}$ \\
\hline Urea (mg/l) & $5.18 \pm 0.01$ & $4.13 \pm 0.16^{* *}$ \\
\hline Creatinine (mg/l) & $0.946 \pm 0.04$ & $5.461 \pm 0.07$ \\
\hline Uric Acid (mg/l) & $4.968 \pm 0.09$ & \\
\hline
\end{tabular}

CTR : control group ; $C B$ : treated group with carbosulfan

Data are expressed as means $\pm S D$ (n=12 rats per group). Comparison between groups was made using unpaired Student " $t$ " test.

$* P<0.05$ versus control group

**P<0.01 versus control group

Table 3: Damage in hematological markers and blood cellularity in male rats treated with CB (Mean \pm SD)

\begin{tabular}{|c|c|c|}
\hline Hematological parameters & CTR & CB \\
\hline $\operatorname{RBC}\left(10^{12} / \mathrm{l}\right)$ & $6.27 \pm 0.8$ & $8.278 \pm 0.829$ \\
\hline HGB (g/l) & $131.8 \pm 12.39$ & $160.333 \pm 1.382 * *$ \\
\hline HCT (\%) & $39.78 \pm 4.38$ & $48.1 \pm 1.677 * *$ \\
\hline MCV (fL) & $61.3 \pm 4.75$ & $60.06 \pm 4.85$ \\
\hline MCH (pg) & $18.4 \pm 1.37$ & $17.6 \pm 0.41$ \\
\hline MCHC (g/l) & $323.25 \pm 10$ & $313.7 \pm 11.88$ \\
\hline PTL $\left(10^{9} / \mathrm{l}\right)$ & $423 \pm 40.4$ & $503 \pm 36.4^{*}$ \\
\hline WBC (cell/ $\mu \mathrm{l})$ & $8200 \pm 283$ & $10533 \pm 828^{*}$ \\
\hline Neutrophil & $1120 \pm 101$ & $1275 \pm 131$ \\
\hline Lymphocyte & $7780 \pm 493$ & $6222 \pm 327 *$ \\
\hline Monocyte & $734 \pm 103$ & $465 \pm 52 *$ \\
\hline
\end{tabular}

CTR : control group ; $C B$ : treated group with carbosulfan

Data are expressed as means $\pm S D$ ( $n=12$ rats per group). Comparison between groups was made using unpaired Student " $t$ ” test.

$* P<0.05$ versus control group

$* * P<0.01$ versus control group 